\title{
Kambin's Triangle Approach of Lumbar Transforaminal Epidural Injection with Spinal Stenosis
}

\author{
Ji Woong Park, M.D., Hee Seung Nam, M.D. ${ }^{1}$, Soo Kyoung Cho, M.D. ${ }^{2}$, Hee Jin Jung, M.D. ${ }^{3}$, \\ Byeong Ju Lee, M.D. ${ }^{3}$, Yongbum Park, M.D. ${ }^{3}$
}

Department of Rehabilitation Medicine, Soonchunhyang University College of Medicine, Seoul 140-887,

${ }^{1}$ Hallym University College of Medicine, Seoul 134-814, ' Samyook Hospital, Gwangju 464-864,

${ }^{3}$ Sanggye Paik Hospital, Inje University College of Medicine, Korea, Seoul 139-707, Korea

\begin{abstract}
Objective To compare the short-term effect and advantage of transforaminal epidural steroid injection (TFESI) performed using the Kambin's triangle and subpedicular approaches.

Method Forty-two patients with radicular pain from lumbar spinal stenosis were enrolled. Subjects were randomly assigned to one of two groups. All procedures were performed using C-arm KMC 950. The frequency of complications during the procedure and the effect of TFESI at 2 and 4 weeks after the procedure between the two groups were compared. Short-term outcomes were measured using a visual numeric scale (VNS) and a five-grade scale. Multiple logistic regression analyses were performed to evaluate the relationship between possible outcome predictors (Kambin's triangle or subpedicular approach, age, duration of symptoms and sex) and the therapeutic effect.

Results VNS was improved 2 weeks after the injection and continued to improve until 4 weeks in both groups. There were no statistical differences in changes of VNS, effectiveness and contrast spread pattern between these two groups. No correlation was found between the other variables tested and therapeutic effect. Spinal nerve pricking occurred in five cases of the subpedicular and in none of the cases of the Kambin's triangle approach $(\mathrm{p}<0.05)$.

Conclusion The Kambin's triangle approach is as efficacious as the subpedicular approach for short-term effect and offers considerable advantages (i.e., less spinal nerve pricking during procedure). The Kambin's triangle approach maybe an alternative method for transforaminal epidural steroid injection in cases where needle tip positioning in the anterior epidural space is difficult.
\end{abstract}

Key Words Kambin's triangle, Lumbar, Transforaminal, Stenosis

Received June 18, 2011; Accepted September 29, 2011

Corresponding author: Yongbum Park

Department of Rehabilitation Medicine, Sanggye Paik Hospital, Inje University College of Medicine, 761-1, Sanggye 6,7-dong, Nowon-gu, Seoul 139707, Korea

Tel: +82-2-950-1390, Fax: +82-2-935-3076, E-mail: swc328@naver.com

() This is an open-access article distributed under the terms of the Creative Commons Attribution Non-Commercial License (http://creativecommons. $\mathrm{org} /$ licenses/by-nc/3.0) which permits unrestricted noncommercial use, distribution, and reproduction in any medium, provided the original work is properly cited.

Copyright $\odot 2011$ by Korean Academy of Rehabilitation Medicine 


\section{INTRODUCTION}

Lumbar spinal stenosis may induce radiating pain in the lower limbs through narrowed intervertebral foramen by a herniated intervertebral disc due to degenerative changes and thickening of the ligamentum flavum, zygapophysial joint and surrounding soft tissues. ${ }^{1-3}$ In addition to mechanical compression, causes of radicular pain in degenerative lumbar spinal stenosis are difficult to explain by one theory. Suggested causes include inflammatory changes around nerve root, venous congestion and hematogenous disability. ${ }^{4,5}$ In the management of radicular pain produced by spinal stenosis, injected steroid is expected to contribute to pain reduction by interrupting the synthesis of prostaglandins, blocking conduction of nociceptive c fibers and controlling edema around the nerve root. ${ }^{6-8}$ Transforaminal approach is preferred for epidural steroid injections, because injection into the relevant nerve root may maximize drug concentration and it is possible to inject toward the anterior extradural space of the nerve root related to symptoms. ${ }^{9,10}$ Currently, the subpedicular approach is the most common method used clinically. In this method, the injection needle is progressed towards the safe triangle under the inferior surface of the pedicle to locate the superolateral spinal nerve related to symptoms. ${ }^{11}$ This location is favored because agents can be injected into the anterior extradural space, i.e. the inflammatory site between the back of the herniated intervertebral disc and the anterior nerve root dural sleeve. The risk of damaging dura mater is decreased, as the injection needle goes through the border of the lateral upper intervertebral foramen. ${ }^{9,12}$ However, Murthy et al. ${ }^{13}$ reported that the Adamkiewicz artery (AKA artery) runs through the safe triangle and injection at this site might transfer agents within the artery or directly damage vessel.

In 1972, Kambin introduced endoscopic intervertebral discectomy by posterolateral approach, defining the Kambin's triangle as the site to approach the intervetebral disc. ${ }^{14}$ The Kambin's triangle is defined as a right triangle over the dorsolateral disc. The hypotenuse is the exiting nerve root, the base (width) is the superior border of the caudal vertebra and the height is the dura/traversing nerve root. ${ }^{14}$ This approach can protect the epidural and nervous system, and prevent chronic nerve edema, epidural bleeding and epidural scarring. ${ }^{15,16}$ Thus, safety can be secured when this site is used for epidural injection. According to Murthy et al. ${ }^{13}$, when the radiculomedullary artery was located by spinal angiography in the intervertebral foramen, $97 \%$ of the cases showed that the artery was located on the upper half of the intervertebral foramen and no artery was found in the area of less than $20 \%$. When the injection needle was located on the site of $<20 \%$ of the intervertebral foramen, the risk of injecting agents into radiculomedullary artery and vessel damage could be prevented.

In this context, the purpose of this study was to compare the subpedicular approach and the approach using Kambin's triangle in transforaminal epidural block performed in patients with spinal stenosis complaining of lumbar radicular pain, and to investigate the shortterm effects and possible complications during injection.

\section{MATERIALS AND METHODS}

\section{Subjects}

The subjects of this study were patients who visited the Department of Rehabilitation Medicine for lumbar nerve root pain between July 12010 and June 31 2011. Inclusion criteria were patients suspected of lumbar nerve root pain by clinical exam, history taking or electromyography; and spinal stenosis on the relevant nerve root evidenced by lumbar computed tomorgraphy (CT) and/or magnetic resonance imaging (MRI). The exclusion criteria were: generalized inflammatory diseases; previous use of anticoagulant agents; uncontrollable diabetes that could induce steroid adverse effects; previous adverse effects to lidocaine and/or contrast agents; current suspected or diagnosed infection; poor general health, making it difficult to visit the hospital regularly; cutaneous disorders around the injection, making it inappropriate for injecting agents; mental problems preventing the patient to answer the questionnaire; previous injection treatment at the same site within the past three months; patients requiring constant drug administration or treatment during the clinical period, using analgesics and anti-inflammatory agents, except for acetaminophen or physiotherapy, thereby making difficult determination of therapeutic effects; and, patients with cauda equine syndrome. 


\section{Randomization}

After collecting information on basic patient characteristics, the subjects $(\mathrm{n}=42)$ were randomly divided into two groups with respect to the approach: subpedicular approach ( $\mathrm{n}=22$; mean age $69.23 \pm 7.98$ years) or Kambin's triangle approach $(\mathrm{n}=20$; mean age $66.95 \pm 7.70$ years). The sex ratio, duration of pain, body mass index (BMI), nerve root as cause and period of prevalence are presented in Table 1. Both options involved the administration of 1 cc of the nonionic contrast agent Omnipaque 300 (GE Healthcare, Carrigtohill, Ireland) $+2 \mathrm{cc}$ of $0.5 \%$ lidocaine $(1.5 \mathrm{ml})+20 \mathrm{mg}$ triamcinolone. Patients showing no therapeutic effects at the 2-week follow-up after the first procedure (patient satisfaction index 0 ) were excluded from the final analysis; those with partial effects (i.e. $<50 \%$ on visual numeric scale (VNS) and a patient satisfaction index of 1 or 2) were re-injected at follow-up.

\section{Method of injection}

Kambin's triangle approach: Kambin's triangle is defined as a right triangle over the dorsolateral disc. The hypotenuse is the exiting nerve root, the base (width) is the superior border of the caudal vertebra, and the height is the dura/traversing nerve root (Fig. 1) ${ }^{14}$ There are several transforaminal approaches using this site, including the retrodiscal approach ${ }^{17}$ and the preganglionic approach. ${ }^{18}$ Nerve root canal is the space that the nerve root occupies from where it is visible to

Table 1. Characteristics of the Patients

\begin{tabular}{lccc}
\hline & $\begin{array}{c}\text { Subpedicular } \\
\text { approach } \\
(\mathbf{n = 2 2 )}\end{array}$ & $\begin{array}{c}\text { Kambin's } \\
\text { triangle } \\
\text { approach } \\
(\mathbf{n = 2 0})\end{array}$ & p-value \\
\hline Age (years) & $69.23 \pm 7.98$ & $66.95 \pm 7.70$ & 0.246 \\
Male & $9(40.9 \%)$ & $8(40.0 \%)$ & \\
Female & $13(59.1 \%)$ & $12(60.0 \%)$ & 0.601 \\
BMI (kg/m $\left.{ }^{2}\right)$ & $23.25 \pm 1.91$ & $23.31 \pm 2.27$ & 0.743 \\
Duration (Month) & $6.45 \pm 2.24$ & $6.85 \pm 2.43$ & 0.558 \\
No of injection & $1.50 \pm 0.51$ & $1.40 \pm 0.50$ & 0.521 \\
Target root & & & \\
L2 & $2(9.1 \%)$ & $3(15.0 \%)$ & \\
L3 & $1(4.5 \%)$ & $1(5.0 \%)$ & \\
L4 & $7(31.8 \%)$ & $7(35.0 \%)$ & \\
L5 & $12(54.5 \%)$ & $9(45.0 \%)$ & 0.911 \\
\hline
\end{tabular}

Values are mean \pm standard deviation

BMI: Body mass index where it leaves the intervertebral foramen. The canal is divided into the entrance, middle and exit zone. The space occupied by the spinal nerve outside the exit zone is called the far lateral zone. ${ }^{19}$

In the subpedicular approach, the agents are injected at the exit zone as the distal site of the nerve root canal; occasionally the agents cannot be delivered into retrodiscal area, as the entrance zone or proximal area is passing through the stenosis area. In the preganglionic approach, it is possible to inject agents at the entrance and middle zone as the main areas of nerve entrapment

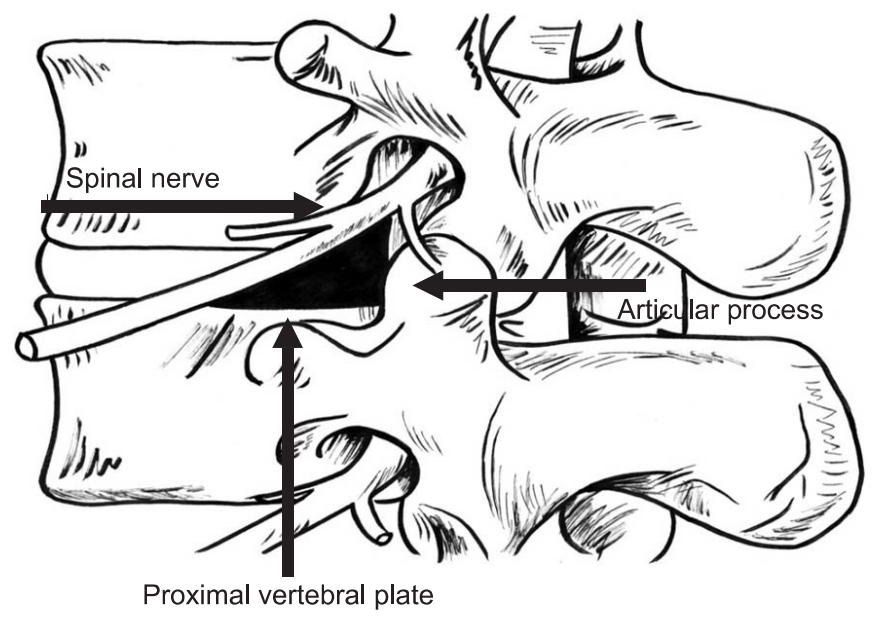

Fig. 1. Schematic description of the "Kambin's triangle". The triangle is defined by the hypotenuse, base, and height. The hypotenuse is the exiting nerve; the base is the caudad vertebral body; and the height is the traversing nerve root.

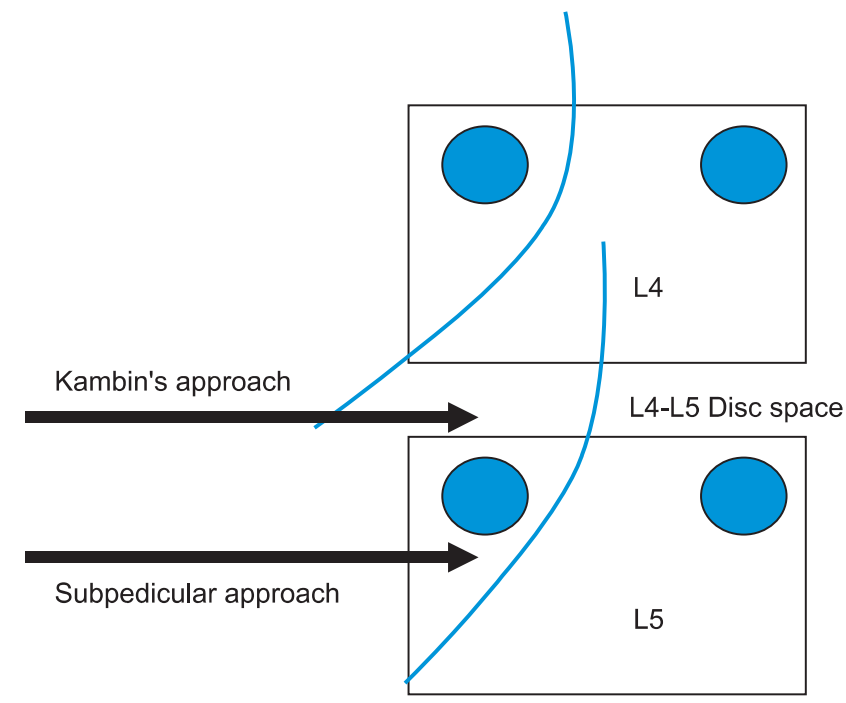

Fig. 2. Schematic description for transforaminal epidural steroid injection with the Kambin's triangle versus the subpedicular approach (target L5 nerve root). 
by injecting at the retrodiscal area of the entrance zone, as proximal area of the targeted nerve root (e.g. when the L5 nerve root is targeted, the agents are injected at the retrodiscal area of L4 and L5, not at the injection area of intervertebral foramen as L5 and S1) (Fig. 2). Such approaches may damage the intervertebral disc because the injection is adjacent to the posterior segment of the intervertebral disc. Thus, in this study, the final target site of injection was determined to be the posterior inferior at the lateral view (Fig. 3).

Patients were placed in the prone position and were supported by pillows under the abdomen to reduce lumbar lordosis. The $\mathrm{X}$ ray projection was focused on the epiphyseal plate of the upper and lower vertebral body by controlling the cranial-caudal angle of the C-arm KMC 950 (KOMED, Kwangju, Korea), and the right and left angle of the C-arm was rotated by 20-35 degrees toward the region, so that the superior articular process could be seen at the middle of the intervertebral disc. At that location, a Spinocan ${ }^{\circledR} 3.5$-inch 22 Gauge spinal needle (BRAUN, Melsungen, Germany) was inserted into the skin toward the lateral lower part of the superior articular process and parallel to the $\mathrm{X}$-ray projection path, and the process was touched, directed laterally and advanced by $2-3 \mathrm{~mm}$. Then, the needle was located medially in the 5 o'clock direction of the upper pedicle at the anteroposterior view, without further advancement and in the posteroinferior of the intervertebral foramen at lateral view. After the final location of the needle was secured, 1 cc of non-ionic contrast agent was administered to observe diffusion location and scope of the contrast agent, and then $2 \mathrm{cc}$ of the prepared agent $(0.5 \%$ lidocaine $1.5 \mathrm{ml}+$ triamcinolone $20 \mathrm{mg})$ was administered (Fig. 4).

Subpedicular approach: All patients were in the prone position and were supported by pillows under the abdomen to reduce lumbar lordosis. The relevant lumbar part was identified by using the Scotty dog shadow oblique view. The lower endplate of the spine for the $\mathrm{C}$-arm was adjusted for accordance and rotated by 15 30 degrees in the oblique view to visualize the Scotty dog shadow. After the site was disinfected, 3.5-inch 22 Gauge spine needle was progressed toward the subjacent pedicle, inferolateral interarticularis (safe triangle) for the superior intervertebral foramen. When the tip of the needle reached the inferolateral border, the $\mathrm{C}$-arm was rotated to the lateral view, and the needle was gradually progressed toward the anterior and superior aspects of the intervertebral foramen. When the needle reached the final location, an aspiration text test was conducted to check for blood detection, and $1 \mathrm{cc}$ of non-ionic contrast agent was administered under real-time fluoroscopy, to identify whether the agent was injected into the anterior epidural space. All procedures were done by
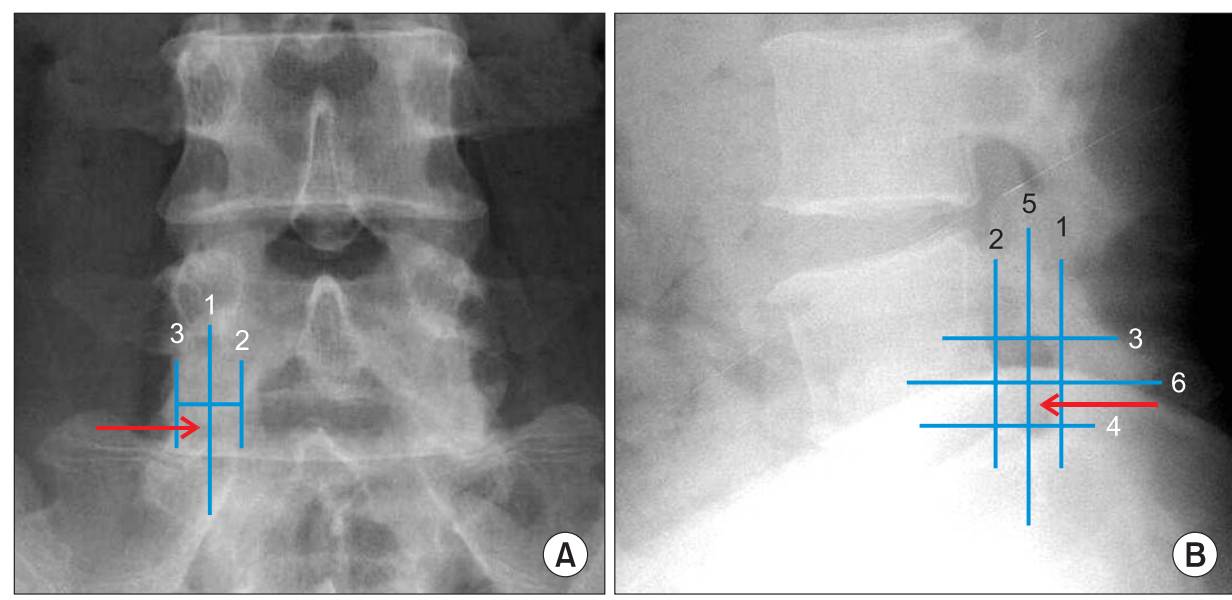

Fig. 3. (A) Anterior-posteior view of the lumbar spine, with superimposed line (1) bisecting the pedicle. This line was drawn halfway between the farthest medial (2) and farthest lateral (3) points on the pedicle. (B) Lateral view of the lumbar spine, with the quadrant system superimposed. First, a line was drawn tangent to the curve of the spine at the level of interest along the posterior vertebral line. (1) A second line (2) was drawn parallel to the third at the posterior margina of the foramen. Next, two lines perpendicular to lines 1 and 2 were drawn at the superior and inferior margins of the foramen (3 and 4 , respectively). Finally, line 5 was drawn bisecting 1 and 2, and, likewise, line 6 bisecting 3 and 4 . This divided the foramen into four quadrants Arrow: needle position. 
the same author; photographs were taken before and after administration of the contrast agent and $2 \mathrm{cc}$ of the agent ( $0.5 \%$ lidocaine $1.5 \mathrm{ml}+$ triamcinolone $20 \mathrm{mg}$ ) was injected (Fig. 5).

\section{Assessment of variables}

All events were recorded during and after injections. The merits and flaws of the two methods were compared by observing diffusion location and scope of the contrast agents, and the discomfort produced by injection. When the agent diffused into the epidural space, the agent diffusing from the injected vertebral body by blocking the needle in the cranial-caudal direction and diffusion to the anterior or posterior epidural space was analyzed on the lateral view. The spinal levels of diffusion of the contrast agent in the epidural space were measured in the cranial-caudal direction and recorded at the upper endplate, middle of the vertebral body and low endplate of the vertebral body. Cases when the agent reached the superior low endplate were contained in the vertebral body below the area, whereas cases when the agent reached the middle vertebral body and the upper endplate were contained in the vertebral body of the area. Similarly, cases when the agent reached the superior endplate and the middle of the vertebral body were contained in the vertebral body above the area, whereas cases when the agent reached the low endplate were contained in the vertebral body of the area.

Pain was assessed before treatment and 2 and 4 weeks after treatment, to compare the short-term therapeutic effects of the two approaches. After 4 weeks, the patient satisfaction index was measured on a 5-point scale, as follows: 0 (no effects), 1 (poor), 2 (normal), 3 (good) and 4 (excellent). "Excellent" meant that the patient was satisfied because the results of the treatment were according to his/her expectation, "good" meant that he/ she was not much satisfied because the results of the treatment were not according to his/her expectation but would undergo the same treatment again in case of pain, "normal" meant that there were some effects but
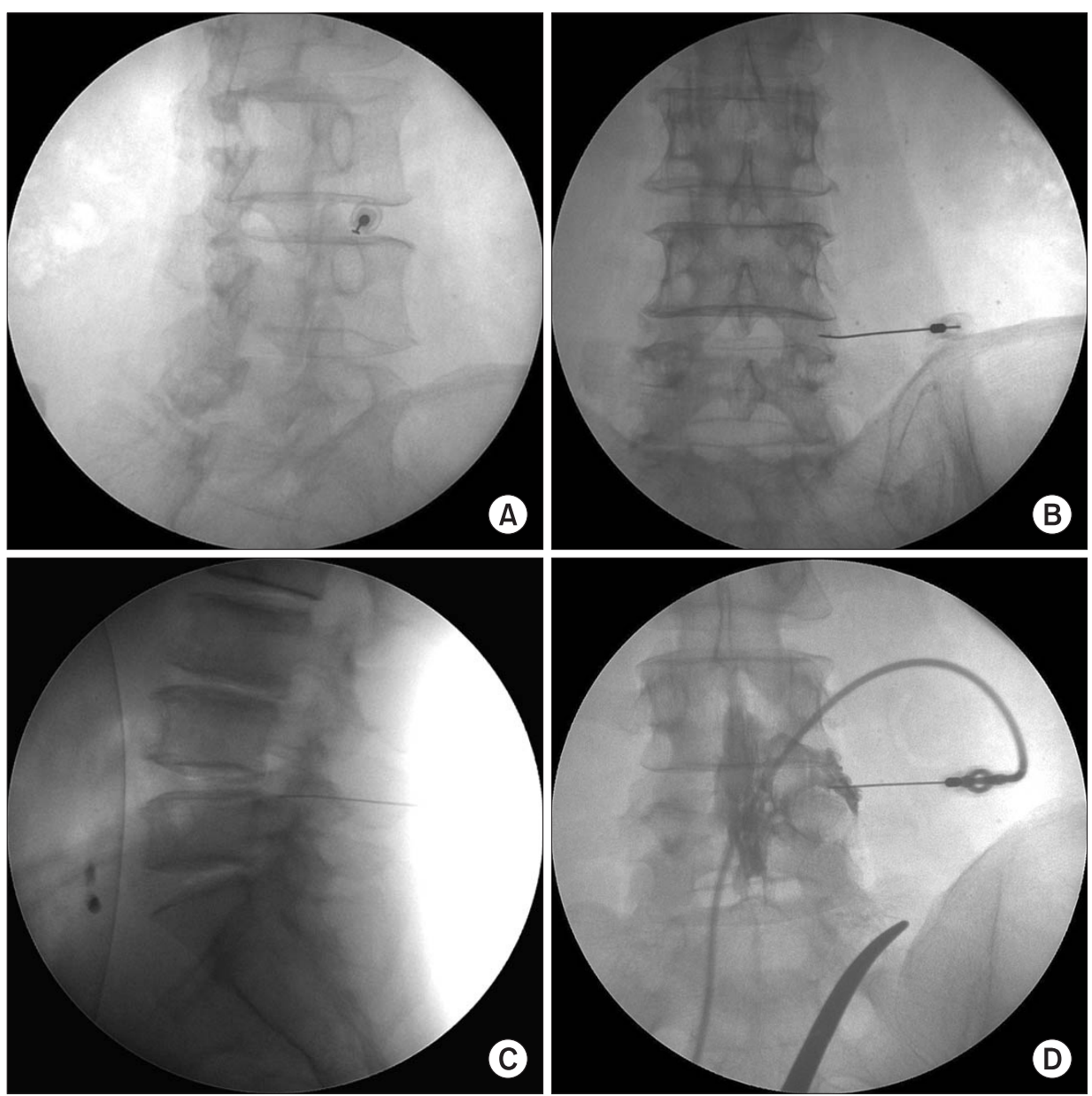

Fig. 4. Kambin's triangle approach of the L5 nerve root. (A) In the oblique view, the needle tip is advanced slowly and cautiously past the superior articular process lateral surface. (B) The anterior-posterior view will most often demonstrate the tip in the interpedicular line. (C) The lateral radiography should also be used while advancing past the SAP to minimize the risk of the penetration until the needle tip is at the posterior and inferior aspect of intervertebral neural foramen. (D) A small amount of contrast is used to confirm epidural spread. 

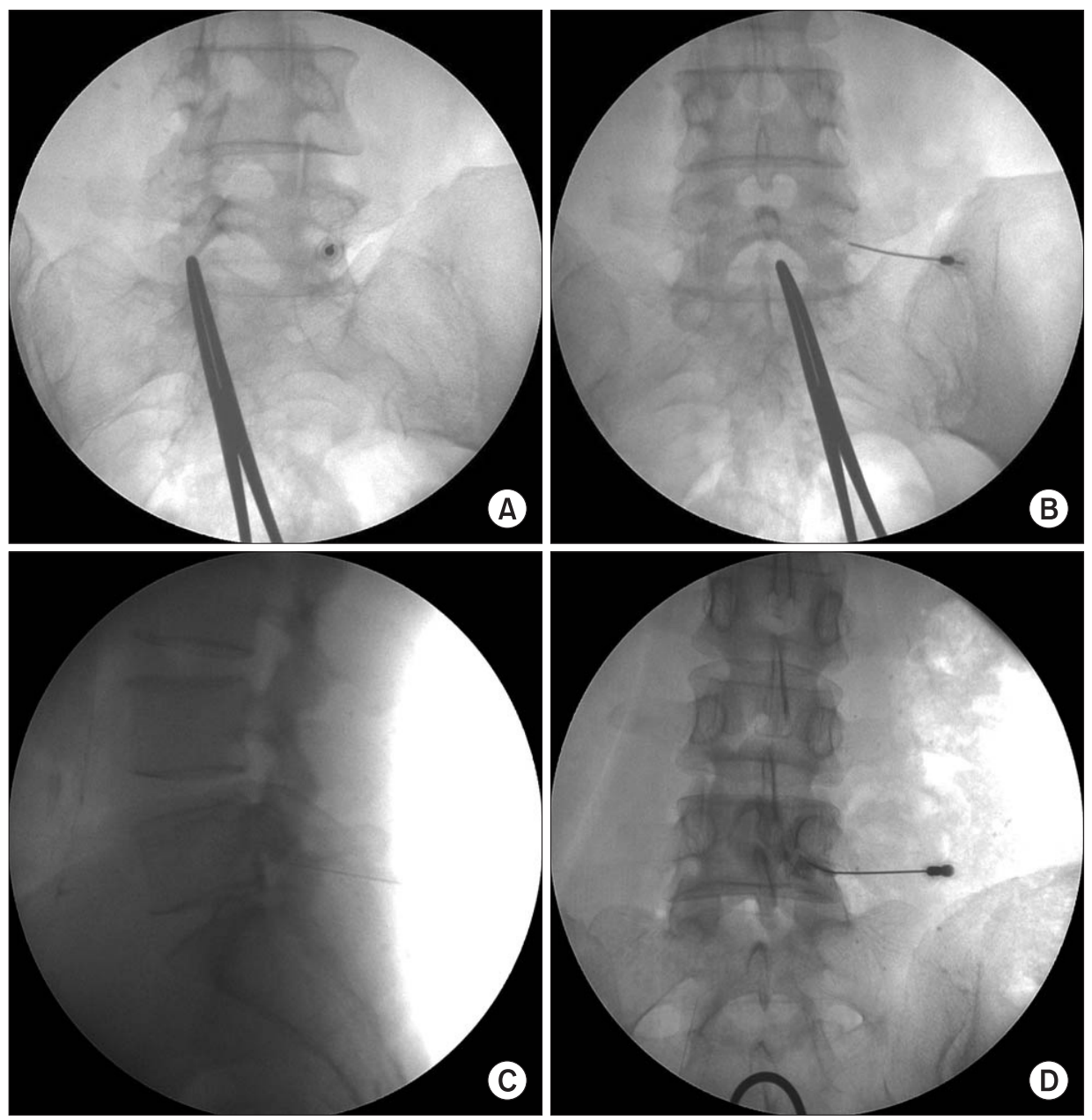

Fig. 5. Subpedicular approach of the L5 nerve root. (A) In oblique view, needle tip lies directly inferior to the pedicle and inferolateral to the pars interarticularis. (B) The anteriorposterior view showing the proper location of the needle at the base of pedicle. (C) The lateral radiography should also be used while the needle is advanced until the needle tip is at the anterior and superior aspect of intervertebral neural foramen. (D) A small amount of contrast is used to confirm epidural spread.

the patient would not select the same treatment in case of pain, and "poor" meant that the effects were similar or less than those of previous treatments.

\section{Statistical analyses}

Gender, BMI, period of prevalence, age, targeted nerve root and diffusion of the contrast agent were compared between the two groups using the chi-square test, Fisher's exact test, and Mann-Whitney U method. Comparisons between the two groups in complications and discomfort that could occur during injection were conducted by Fisher's exact test. Comparison of the numeric rating scale (NRS) between the two groups was conducted by repeated measures analysis of variance (ANOVA), and Bonferroni's correction was applied post-hoc. By using logistic regression, correlations between success of treatment and several variables (method of injection, age, gender and period of prevalence) were analyzed. SAS Enterprise Guide 4.1 (4.1.0.471) software was used for statistical analysis, and statistical significance level was set at $\mathrm{p}<0.05$.

\section{RESULTS}

\section{Patient flow}

We investigated a total of 52 patients, and six were excluded because after applying our exclusion criteria. One patient from the subpedicular approach and one from the Kambin's triangle approach were excluded because medication was used during the research period. Other two patients were excluded because it was difficult for them to visit the hospital regularly.

\section{Short-term therapeutic effects and patient satisfaction} before and after injection

The short-term treatment effects significantly declined in both groups at 2 and 4 weeks after the procedure. However, there was no significant difference between the 
Table 2. Comparison of the Effect on NRS by the Steroid Injection

\begin{tabular}{lccc}
\hline & Baseline & 2 weeks after injection & 4 weeks after injection \\
\hline Subpedicular approach & $7.25 \pm 0.58$ & $2.94 \pm 0.45^{*}$ & $2.31 \pm 0.48^{*}$ \\
Kambin's triangle approach & $7.11 \pm 0.69$ & $2.92 \pm 0.55^{*}$ & $2.20 \pm 0.52^{*}$ \\
\hline
\end{tabular}

Values are mean \pm standard deviation

NRS: Numeric rating scale

${ }^{*} \mathrm{p}<0.05$ : Comparison of before vs after injection

Table 3. Forte and Foible during the Procedure

\begin{tabular}{lccc}
\hline & $\begin{array}{c}\text { Subpedicular approach } \\
(\mathbf{n}=\mathbf{2 2})\end{array}$ & $\begin{array}{c}\text { Kambin's triangle approach } \\
(\mathbf{n}=\mathbf{2 0})\end{array}$ & p-value* \\
\hline Spinal nerve pricking & 5 & 0 & 0.023 \\
Intra-vascular injection & 4 & 3 & 0.782 \\
Discal injection & 2 & 0 & 0.167 \\
\hline
\end{tabular}

${ }^{*}$ Compared by Fisher's exact test

Table 4. Vertebral Spreading Range of Contrast in the Study Patients

\begin{tabular}{lccc}
\hline & $\begin{array}{c}\text { Subpedicular approach } \\
(\mathbf{n = 2 2})\end{array}$ & $\begin{array}{c}\text { Kambin's triangle approach } \\
(\mathbf{n = 2 0})\end{array}$ & p-value \\
\hline Cephalad spreading segment & $1.32 \pm 0.48$ & $1.15 \pm 0.37$ & 0.211 \\
Caudad spreading segment & $1.14 \pm 0.35$ & $1.35 \pm 0.49$ & 0.110 \\
Total spreading segment & $1.59 \pm 0.67$ & $1.60 \pm 0.75$ & 0.967 \\
\hline
\end{tabular}

Values are mean \pm SD or number of patients $\mathrm{p}<0.05$

Mann Whitney U test

two groups in initial pain, pain after 2 weeks and pain changes after 4 weeks (Table 2). Similarly, there was no statistical difference between the two groups in patient satisfaction index and therapeutic success assessed after four weeks ( $p>0.05)$.

\section{Complications during injection}

Nerve root pricking during injection showed significant differences: five cases were reported in the subpedicular approach, whereas no case was found in the Kambin's triangle approach. As for intravascular injection, four cases were found in the conventional subpedicular approach and three cases were found in the Kambin's triangle approach, with no significant difference between the two (Table 3). Both groups did not present nerve root damage as a complication, and injection into the intervertebral disc was found in two cases of the subpedicular approach. Other severe complications were not shown. Patients with dizziness and temporary muscular weakness were moved to the recovery room for observation, and all symptoms were absent at discharge. The five patients with nerve root pricking did not show nerve root damage at the 2 -week follow-up visit.

\section{Diffusion scope of the contrast agent}

In the subpedicular approach, on lateral view, the contrast agent diffused only to the anterior epidural space in 18 patients $(81.8 \%)$, to the posterior epidural space only in one patient $(4.5 \%)$ to the anterior and posterior epidural spaces in three patients (13.6\%). In total, the contrast agent diffused into the anterior epidural space in 21 (95.5\%) patients. In the Kambin's triangle approach, $12(60.0 \%)$ patients showed contrast agent diffusion into the anterior epidural space only; there was no case with contrast agent diffusion to the posterior epidural space only, and eight (40.0\%) patients showed diffusion of the contrast agent to the anterior and posterior epidural space. In total, the contrast agent diffused to the anterior epidural space in $20(100 \%)$ patients. No statistical difference was found in diffusion scope of the 
Table 5. Multiple Logistic Regression Analysis for Possible Outcome Predictors for Injection Effectiveness at Shortterm Follow-up

\begin{tabular}{lccc}
\hline \multicolumn{1}{c}{ Factor } & Odds ratio & 95\% confidence interval & p-value \\
\hline Kambin's triangle versus & 0.280 & $0.057-1.376$ & 0.117 \\
\hline Subpedicular approach & & & \\
\hline Gender & 0.261 & $0.055-1.227$ & 0.089 \\
\hline Age $($ years $)$ & 1.001 & $0.901-1.111$ & 0.991 \\
\hline BMI $\left(\mathrm{kg} / \mathrm{m}^{2}\right)$ & 1.008 & $0.693-1.465$ & 0.967 \\
\hline Duration & 0.966 & $0.682-1.368$ & 0.844 \\
\hline
\end{tabular}

BMI: Body mass index

contrast agent between the two approaches ( $\mathrm{p}>0.05)$. In the subpedicular approach, on anteroposterior epidural contrast, the contrast agent diffused by $1.59 \pm 0.67$ spinal level generally ( $1.32 \pm 0.48$ spinal level cranially and $1.14 \pm 0.35$ spinal level caudally). In the Kambin's triangle approach, the contrast agent diffused by $1.60 \pm 0.75$ spinal level generally $(1.15 \pm 0.37$ spinal level cranially and $1.35 \pm 0.49$ spinal level caudally). There was no statistically significant difference between the two groups (Table 4).

\section{Correlations between treatment effects and various factors}

Treatment was successful when the digit pain degree was $50 \%$ or more and the patient satisfaction index was 3 or 4 , at 4 weeks after the injection. No correlations were found between the success rate and several investigated factors, such as injection method, age, gender and prevalence period (Table 5).

\section{DISCUSSION}

Spinal stenosis is a condition produced by compression of the nerve root due to narrowness of the spinal canal and nervous canal following spine fracture, thickness of zygapophysial joint and ligamentum flavum and ossification of posterior longitudinal ligament. ${ }^{1-3}$ There are physical factors of narrowing spinal canal by congenital or degenerative causes or spondyloysis, and venous congestion may be induced around the nerve. In addition, increased permeability of the cell membrane produced by nutritional disorder and inflammatory mediators may induce edema in the nerve root, leading to pain and numbness in the hips and lower limbs. ${ }^{4}$ Patients with degenerative spinal stenosis are usually old, so that they can be treated by drugs, epidural nerve block and kinesitherapy, rather than by surgery. As for the effects of epidural nerve blockage, Delport et al. ${ }^{20}$ reported that steroid injection using the caudal approach and transforaminal approach alleviated pain in a third of the subjects and half of the patients improved in functions. In a prospective, double-blind, randomly-assigned study, Riew et al. ${ }^{21}$ reported that, in patients with spinal stenosis, steroid injection using transforaminal approach by the $\mathrm{C}$-arm showed clinical improvements during the observation period (15-28 months). Thus, epidural steroid injections for spinal stenosis had clinical effects, and the transforaminal approach, when compared to others, was effective in improving symptoms with smaller amount of agents, because the agents could easily reach the targeted nerve root, dorsal root ganglion and the anterior of epidural space. ${ }^{22,23}$ However, the transforaminal approach may induce severe complications during the procedure, including steroid injection into vessels, vessel convulsion by direct damage by the needle and ischemic spinal nerve damage by embolism. ${ }^{24,25}$ To date, 12 published cases have reported severe neurological damage by lumbar, dorsal and transforaminal steroid epidural injection. ${ }^{25}$ Glaser and Falco ${ }^{25}$ reported the first case of lower limb paralysis by ischemic spinal damage after lumbar, dorsal and intervertebral foramen steroid epidural injection, even when the needle was located in the safe triangle by the subpedicular approach. Such reports required reexamination of the transforaminal approach through the safe triangle. ${ }^{26}$

As for the lumbar spinal nerve, there is a triangle area in which the nerve leaves the intervertebral foramen obliquely to form the hypotenuse, the connected line to the lower part of the pedicle is the bottom side, and the line forming a right angle against the exterior of the pedicle is the vertical plate. This area is called "the safe 
triangle," because the space mainly contains only the spinal nerve and vessels. ${ }^{11}$ However, the structure of the safe triangle excludes the anatomical structure of artery. ${ }^{26}$ The most dangerous radiculomedullary artery in lumbar transforaminal injection is the AKA artery. In $80 \%$ of healthy people, when penetrating the spinal canal, the artery enters the intervertebral foramen between left T9 (9th thoracic vertebra) and L1 (1st lumbar vertebra). However, care should be taken because in about $20 \%$ of cases it enters the intervertebral foramen between L2 and L4. The main trunk of the AKA enters the medial spinal canal through either the mid or the rostral portion of the foramen. There it passes through the proximal portion of the dorsal root ganglion and the ventral root complex. ${ }^{27}$ Therefore, the subpedicular approach is likely to damage blood vessels such as the AKA or to trigger complications, such as spinal cord infarction resulting from the intravascular injection of particulate steroids, because the injection needle is placed in the anterior superolateral aspect of the intervertebral foramen. In a retrospective study, Murthy et al. ${ }^{13}$ identified the location of the AKA artery within the neural foramen by using spinal vessel angiography of the digital subtraction angiography. They identified the AKA by dividing the neural foramen into 10 parts, and $97 \%$ of the cases showed that the AKA was located on the upper half and no artery was found in the area of the lower $10 \%$. Also, they identified that the AKA was located in the safe triangle on anteriorposterior view, confirming that steroid injection within the AKA and vessel convulsion and embolism by direct damage to vessels could be prevented when the needle was targeted to the lower part of the neural foramen in lumbar transforaminal injection. ${ }^{13}$ However, in this study, no statistical differences were found in intravenous injection of the contrast agent between the two groups. Because the posteromedial venous plexus among the venous plexus within the spine is located between the posterior dura mater and epidural adipose layer, and intravenous injection of agent can occur even though the needle is located in the lower part, escaping the anterior superolateral of the intervertebral foramen that the AKA may pass through. ${ }^{28}$ Desirable effects cannot be expected when the agents are injected within the vessels of venous plexus. Therefore, intravenous diffusion of contrast agents should be identified in transforaminal injection, regardless of approaches.
The Kambin's triangle is defined as a right triangle over the dorsolateral disc. The hypotenuse is the exiting nerve root, the base (width) is the superior border of the caudal vertebra, and the height is the dura/traversing nerve root. ${ }^{14}$ The triangle is where endoscopic lumbar intervertebral disc excision is conducted posterolaterally. Approaches used in this area have several merits, including increased safety, such as protection of epidural and nervous system, prevention of venous congestion and chronic nervous edema and prevention of epidural bleeding and scarring in tissues around the nerve and epidural. ${ }^{14-16}$ There are some methods of transforaminal epidural injections for this area, including the preganglionic and retrodiscal approaches. ${ }^{17,18}$ However, the retrodiscal approach has a higher risk for injection of contrast agent into the intervertebral disc, because the agent is injected near the disc, an injection that may induce diskitis as complications. Therefore, we finally placed the needle in the posteroinferior of the intervertebral foramen on the lateral view. As a result, two cases of injecting the contrast agent into the intervertebral disc were found in the subpedicular approach, but no cases in the Kambin's triangle approach. Both patients did not develop complications, such as diskitis.

The Kambin's triangle approach was thought to provide reduced therapeutic effects, because the agent was injected into the lateral epidural space, but in this study no statistical difference was found between the two methods. The agent was considered to be sufficiently injected to the region, as the agent diffused to the anterior epidural space on the anteroposterior and lateral view. In a retrospective study, Crall et al. ${ }^{29}$ reported no statistical differences in the immediate treatment effects from injections into four parts of the intervertebral foramen, noting that the preganglionic approach did not show difference or superiority in treatment effects when compared to the existing subpedicular approach. ${ }^{30,31}$ According to Jeong et al., ${ }^{31}$ the preganglionic approach was superior to the subpedicular approach in treatment effects after 4 weeks, a result that may have been caused by the fact that the clinical group had more patients with herniated intervertebral disc than patients with spinal stenosis. As mentioned before, the preganglionic approach may be more effective for patients with herniated intervertebral disc, because the needle can 
be placed closer to the nerve root compressed by the herniated intervertebral disc. We expected that the results of this study might be different in effects from those of Jeong et al. ${ }^{31}$ because all the subjects were at least 50 years old with spinal stenosis and the final location of the needled was different. However, the treatment effects were not clearly different from those of the subpedicular approach.

In the subpedicular approach, the needle is located in the anterior of the intervertebral foramen crossing the nerve root. Thus, it may prick the spinal nerve root during injection because it is difficult for the needle to be located in the anterior epidural space through the safe triangle in severe spinal stenosis, epidural fibrosis, and sunken degenerative intervertebral disc region. ${ }^{32}$ Meanwhile, in the Kambin's triangle approach, the needle is located in the inferior-posterior on lateral view, reducing the risk of pricking the spinal nerve root. In this study, there were five cases of spinal nerve root pricking in the subpedicular approach in patients with severe spinal stenosis and with severely lowering of intervertebral disc, whereas no pricking was reported in the Kambin's triangle approach $(\mathrm{p}<0.05)$.

We did not compare the long-term treatment effects and functional effects of the Kambin's triangle and the subpedicular approach, but compared the complications and benefits/weaknesses during injection. As this study compared only the short-term effects for four weeks, it is needed to compare long-term treatment effects for at least six months in the future.

\section{CONCLUSION}

Epidural block using the Kambin's triangle approach could reduce nerve root pricking during the procedure, but presently did not show any significant difference in short-term therapeutic effects when compared to the subpedicular approach. The approach could an alternative to the subpedicular approach in severe spinal stenosis, epidural fibrosis and sunken degenerative intervertebral disc lesion, when it is hard to place the needle in the anterior epidural space through the safe triangle.

\section{ACKNOWLEDGEMENTS}

This work was supported by 2010 research grant from Inje University.

\section{REFERENCES}

1. Grubb SA, Lipscomb HJ, Coonrad RW. Degenerative adult onset scoliosis. Spine 1988; 13: 241-245

2. Grubb SA, Lipscomb HJ, Suh PB. Results of surgical treatment of painful adult scoliosis. Spine 1994; 15: 1619-1627

3. Jackson RP, McManus AC. Radiographic analysis of sagittal plane alignment and balance in standing volunteers and patients with low back pain matched for age,sex, and size. A prospective controlled clinical study. Spine 1994; 19: 1611-1618

4. Rydevik B, Brown MD, Lundborg G. Pathoanatomy and pathophysiology of nerve root compression. Spine 1984; 9: 7-15

5. Olmarker K, Redevik B, Holm S. Edema formation in spinal nerve roots induced by experimental, graded compression. An experimental study on the pig cauda equina with special reference to differences in effects between rapid and slow onset of compression. Spine 1989; 14: 569-573

6. Kantrowitz F, Robinson DR, McGuire MB, Levine L. Corticosteroids inhibit prostaglandin production by rheumatoid synovia. Nature 1975; 258: 737-739

7. Fukusaki M, Kobayashi I, Hara T, Sumikawa K. Symptoms of spinal stenosis do not improve after epidural steroid injection. Clin J Pain 1998; 14: 148151

8. Johansson A, Hao J, Sjolund B. Local corticosteroid application blocks transmission in normal nociceptive C-fibres. Acta Anaesthesiol Scand 1990; 34: 335-338

9. Slipman CW, Chow DW. Therapeutic spinal corticosteroid injections for the management of radiculopathies. Phys Med Rehabil Clin N Am 2002; 13: 697711

10. Vad VB, Bhat AL, Lutz GE, Cammisa F. Transforaminal epidural steroid injections in lumbosacral radiculopathy: a prospective randomized study. Spine 2002; 27: 11-16

11. Manchikanti L, Cash KA, Pampati V, Damron KS, 
McManus CD. Evaluation of lumbar transforaminal epidural injections with needle placement and contrast flow patterns: a prospective, descriptive report. Pain Physician 2004; 7: 217-223

12. Botwin KP, Gruber RD, Bouchlas CG, Torres-Ramos FM, Sanelli JT, Freeman ED, Slaten WK, Rao S. Fluoroscopically guided lumbar transforaminal epidural steroid injections in degenerative lumbar stenosis: an outcome study. Am J Phys Med Rehabil 2002; 81: 898-905

13. Murthy NS, Maus TP, Behrns CL. Intraforaminal location of the great anterior radiculomedullary artery (artery of Adamkiewicz): a retrospective review. Pain Med 2010; 11: 1756-1764

14. Kambin P, Sampson S. Posterolateral percutaneous suction-excision of herniated lumbar intervertebral discs. Report of interim results. Clin Orthop Relat Res 1986; 207: 37-43

15. Kambin P. Arthroscopic microdiskectomy. Mt Sinai J Med 1991; 58: 159-164

16. Kambin P, Savitz MH. Arthroscopic microdiscectomy: an alternative to open disc surgery. Mt Sinai J Med 2000; $67: 283-287$

17. Jasper JF. Lumbar retrodiscal transforaminal injection. Pain Physician 2007; 10: 501-510

18. Lew HL, Coelho P, Chou LH. Preganglionic approach to transforaminal epidural steroid injections. Am J Phys Med Rehabil 2004; 83: 378

19. Lee CK, Rauschning W, Glenn W. Lateral lumbar spinal canal stenosis: classification, pathologic anatomy and surgical decompression. Spine 1988; 13: 313-320

20. Delport EG, Cucuzzella AR, Marley JK, Pruitt CM, Fisher JR. Treatment of lumbar spinal stenosis with epidural steroid injections: a retrospective outcome study. Arch Phys Med Rehabil 2004; 85: 479-484

21. Riew KD, Yin Y, Gilula L, Bridwell KH, Lenke LG, Lauryssen C, Goette K. The effect of nerve-root injections on the need for operative treatment of lumbar radicular pain. A prospective, randomized, controlled, double-blind study. J Bone Joint Surg Am 2000; 82: 1589-1593
22. Boswell MV, Hansen HC, Trescot AM, Hirsch JA. Epidural steroids in the management of chronic spinal pain and radiculopathy. Pain Physician 2003; 6: 319334

23. Manchikanti L. Transforaminal lumbar epidural steroid injections. Pain Physician 2000; 3: 374-398

24. Houten JK, Errico TJ. Paraplegia after lumbosacral nerve root block: report of three cases. Spine J 2002; 2: 70-75

25. Glaser SE, Falco F. Paraplegia following a thoracolumbar transforaminal epidural steroid injection. Pain Physician 2005; 8: 309-314

26. Glaser SE, Shah RV. Root cause analysis of paraplegia following transforaminal epidural steroid injections: the 'unsafe' triangle. Pain Physician 2010; 13: 237-244

27. Alleyne CH Jr, Cawley CM, Shengelaia GG, Barrow DL. Microsurgical anatomy of the artery of Adamkiewicz and its segmental artery. J Neurosurg 1998; 89: 791795

28. Groen RJ, Groenewegen HJ, van Alphen HA, Hoogland PV. Morphology of the human internal vertebral venous plexus: a cadaver study after intravenous Araldite CY 221 injection. Anat Rec 1997; 249: 285-294.

29. Crall TS, Gilula LA, Kim YJ, Cho Y, Pilgram T, Riew KD. The diagnostic effect of various needle tip positions in selective lumbar nerve blocks: an analysis of 1202 injections. Spine 2006; 31: 920-922

30. Lee JW, Kim SH, Choi JY, Yeom JS, Kim KJ, Chung SK, Kim HJ, Kim C, Kwack KS, Kwon JW, et al. Transforaminal epidural steroid injection for lumbosacral radiculopathy: preganglionic versus conventional approach. Korean J Radiol 2006; 7: 139-144

31. Jeong HS, Lee JW, Kim SH, Myung JS, Kim JH, Kang HS. Effectiveness of transforaminal epidural steroid injection by using a preganglionic approach: a prospective randomized controlled study. Radiology 2007; 245: 584-590

32. Lee IS, Kim SH, Lee JW, Hong SH, Choi JY, Kang HS, Song JW, Kwon AK. Comparison of the temporary diagnostic relief of transforaminal epidural steroid injection approaches: conventional versus posterolateral technique. AJNR 2007; 28: 204-208 